\title{
Prognostic value of MUC4 for mass-forming intrahepatic cholangiocarcinoma after hepatectomy
}

\author{
CHUN-NAN YEH ${ }^{1}$, SEE-TONG PANG ${ }^{2}$, REN-CHING WU $^{3}$, \\ TSUNG-WEN CHEN $^{1}$, YI-YIN JAN ${ }^{1}$ and MIIN-FU CHEN ${ }^{1}$
}

${ }^{1}$ Department of Surgery, ${ }^{2}$ Division of Urology, ${ }^{3}$ Department of Pathology, Chang Gung Memorial Hospital, Chang Gung University, Taoyuan, Taiwan, R.O.C.

Received June 27, 2008; Accepted August 26, 2008

DOI: 10.3892/or_00000188

\begin{abstract}
Cholangiocarcinoma (CCA), a lethal malignancy afflicting many thousands of patients throughout the world, develops through a multi-step progression. We have established an oral thioacetamide-induced model of rat CCA recapitulating the histologic progression of human CCA, especially for mass-forming CCA (MF-CCA). Our previous DNA microarray study showed MUC4 is overexpressed in rat CCA. Herein, we investigated the prognostic value of MUC4 for predicting overall survival rate (OS) for MFCCA patients undergoing hepatectomy. Overexpression of MUC4 in rat CCA is demonstrated by RT-PCR. From the archives of Chang Gung Memorial Hospital, 53 MF-CCA patients undergoing hepatectomy were selected for an immunohistochemical study of MUC4. Fifteen clinicopathological variables (including MUC4 staining status) were used for survival analysis. MUC 4 is overexpressed in rat CCA. Fifty-three MF-CCA patients, 26 men and 27 women, with a median age of 60 years (range: 29-89) were studied. During the median follow-up duration of 14.7 months, the OS rates at 1, 3, and 5 years were $58.8,25.5$, and $16.5 \%$, respectively. Univariate analysis showed that an absence of physical findings, better nutritional status, small tumor size, negative lymph node metastasis, an absence of MUC4 staining, and curative hepatic resection were associated with favorable OS rate for MF-CCA patients after hepatectomy. However, multivariate Cox proportional hazard analysis showed that an absence of MUC4 staining, small tumor size, and curative hepatectomy independently predicted MF-CCA patients with favorable OS rate after hepatectomy. In conclusion, an absence of MUC4 staining, small tumor size, and curative hepatectomy could independently predict MFCCA patients with favorable OS rate after hepatectomy.
\end{abstract}

Correspondence to: Dr Miin-Fu Chen, Department of Surgery, Chang Gung Memorial Hospital, Chang Gung University, 5 FuHsing Street, Kwei-Shan, Taoyuan, Taiwan, R.O.C.

E-mail: ycn@adm.cgmh.org.tw

Key words: MUC4, hepatectomy, mass-forming cholangiocarcinoma

\section{Introduction}

Peripheral cholangiocarcinoma (CCA) is a malignant tumor occurring in the liver or arising from the second or more distal branches of the intrahepatic bile ducts (1). The incidence of CCA exhibits wide geographical variation, and generally accounts for between 5 and $30 \%$ of primary liver cancers (1). CCA can be grossly classified into mass forming (MF), periductal infiltrating, and intraductal papillary types (2). The MF type creates an apparent lesion in the liver, with frequent recurrence in the remnant liver after hepatic resection.

Clinically, CCA remains challenging and typically presents as an advanced disease. Curative resection with clear margins and without vascular or lymphatic invasion is infrequent and recurrence is common. Although liver transplantation has provided an alternative in the surgical management of $\mathrm{CCA}$, high rates of $\mathrm{CCA}$ recurrence following transplantation limit liver transplantation for CCA patients (2). Tumor biological behavior and early intrahepatic and extrahepatic spread limit the efficacy of surgery. Three-to five-year survival rates, even with resection, remain dismal (3-8). Moreover, radiation therapy or chemotherapy does not significantly improve long-term survival rates $(6,9)$.

Significant progress has been made over the past decade in defining molecular alterations associated with CCA. Recent studies suggest that alterations in the tyrosine kinase receptors c-Erb-2/c-Neu and c-Met, along with possible aberrant autocrine expression of hepatocyte growth factor/ scatter factor, may play a crucial role in the pathogenesis of human CCA (10-12). We had previously developed a reliable rat model of CCA obtained via oral administration of thioacetamide (13). Since it recapitulates the dysplasiacarcinoma sequence of human CCA, this model is useful in shedding more light on the genetic basis of cholangiocellular neoplasia (13).

Gene expression profiling using a DNA microarray is a powerful technique for understanding the molecular abnormalities underlying cancer. In our previous study (data not shown), we identified many differentially expressed genes of rat CCA, which could help us clarify the mechanism of carcinogenesis caused by TAA. Interestingly, among these genes we found MUC4 is over-expressed in rat CCA compared with the non-tumor liver tissue. 
Mucins (MUC) are glycoproteins with oligosaccharides attached to serine or threonine residues of the mucin core protein backbone by O-glycosidic linkage. Human mucin core proteins, including MUC1 to MUC9, MUC11 to13, and MUC15 to17, were identified thereafter (14-21). MUC4 was first reported as tracheobronchial mucin (22), and could be found expressed in various normal tissues (23-26). MUC4 was also proved to be an intramembrane ligand for receptor tyrosine kinase ErbB2, which is highly homologous with the epidermal growth factor receptor (27-29).

Like MUC1, MUC4 is a poor prognostic factor in various human tumors (30-32). In biliary epithelial cells, MUC4 was not expressed in the normal epithelium but in $67 \%$ of CCA (33). However, the relationship between MUC4 expression and the patient's prognosis in MF-CCA is not well defined (34). Therefore, in this study we analyzed the potential role of MUC4 as a candidate for one of the poor prognostic factors in MF-CCA patients undergoing hepatectomy.

\section{Materials and methods}

Quantitative real-time PCR. Quantitative real-time PCR (Q-RT-PCR) reactions were performed using SYBR GreenSuperMix (BioRad, Hercules, CA, USA) in $20 \mu 1$ total volume and a BioRad iCycler iQ real-time detection system according to the manufacturer's instructions. The primers were designed using Beacon Designer software (Premier Biosoft International) and showed as follows: MUC4:
A

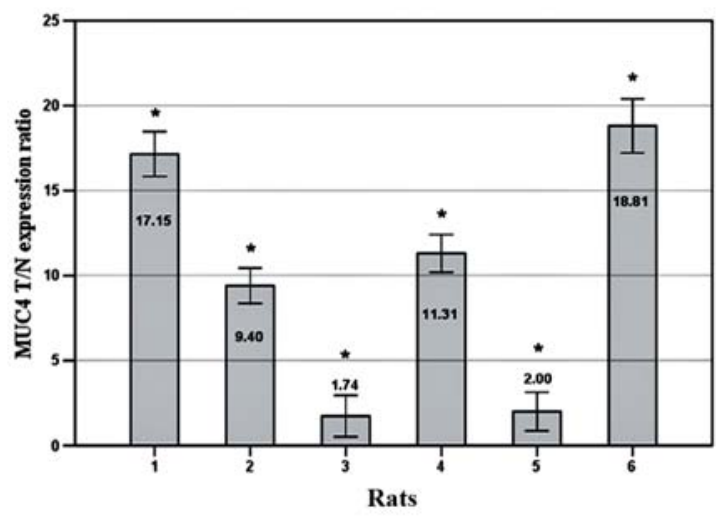

B

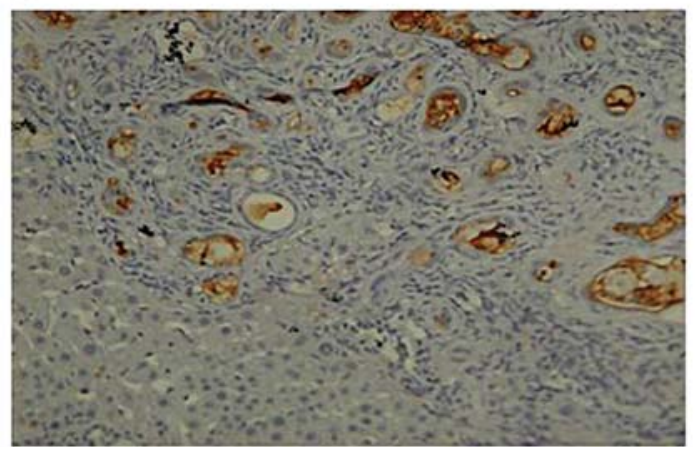

Figure 1. (A) Real-time PCR for MUC4 expression of six paired tissue of non-tumor liver and tumor obtained from six rats. Significantly higher expression of MUC4 gene was noted (means significance; $\left.{ }^{*} \mathrm{p}<0.05\right)$. (B) Immunohistochemical staining of MUC4 in rat CCA (x200).
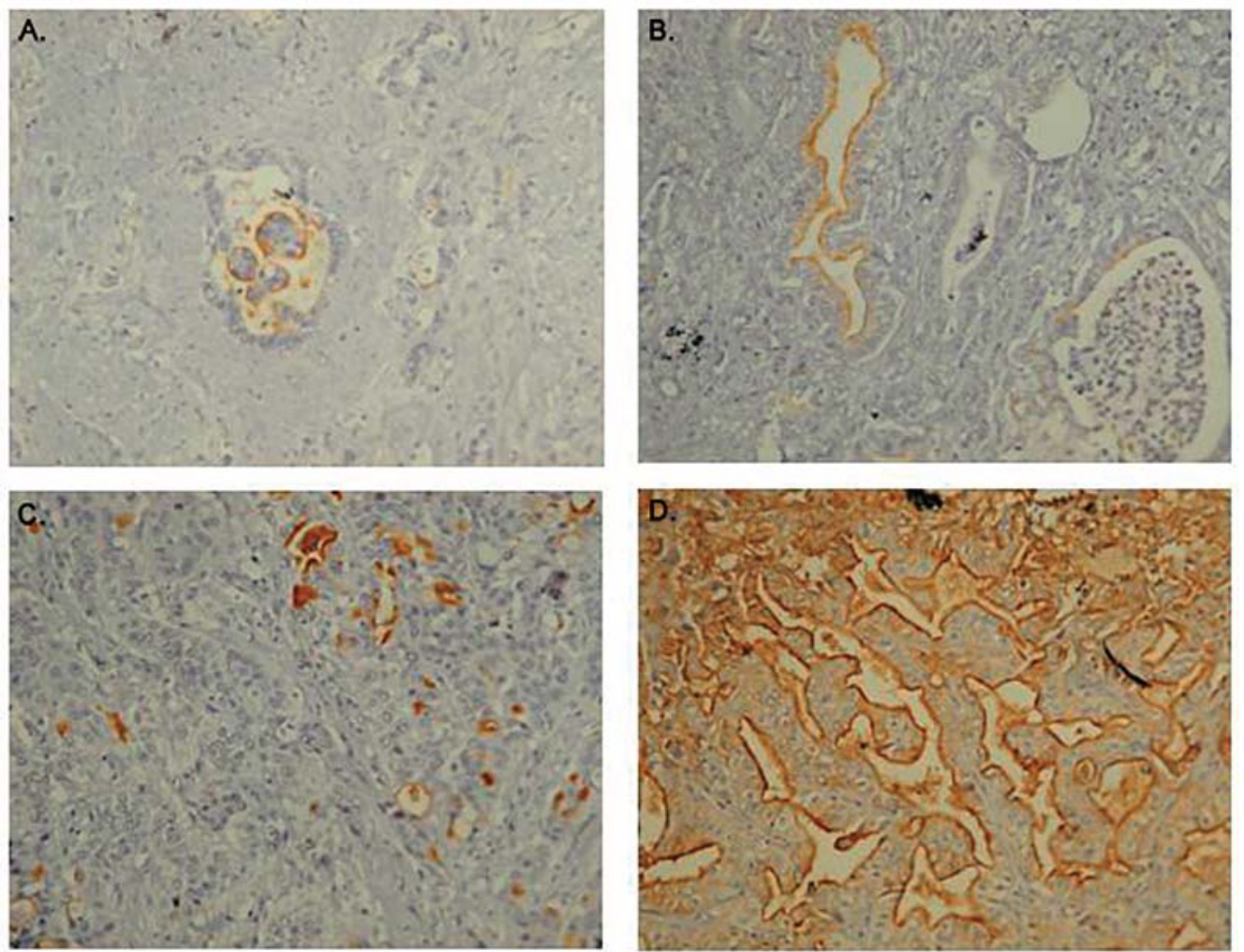

Figure 2. Immunohistochemical staining validation of overexpressed MUC4 in human CCA: MUC4 is diffusely expressed in a cytoplasmic and membranous distribution in human CCA but absent in normal hepatocyte. Various positive strength of immunohistochemical staining of MUC4 in human CCA from 1 positive, 2 positive, 3 positive to 4 positive (A-D, respectively) (x200). 
A.

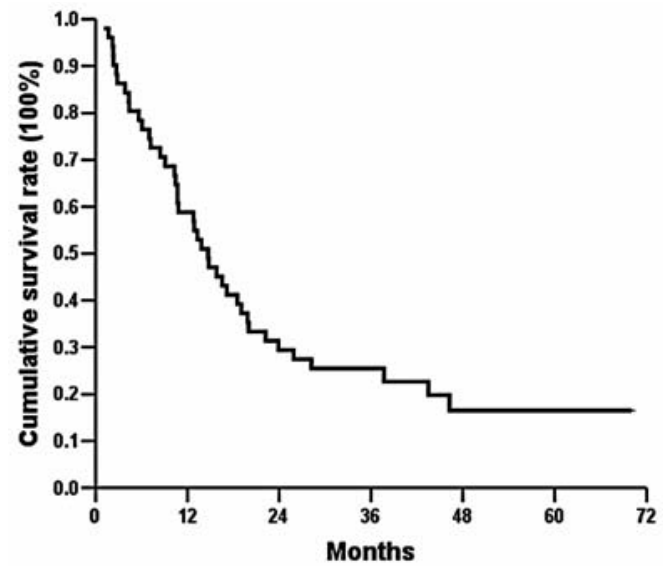

C.

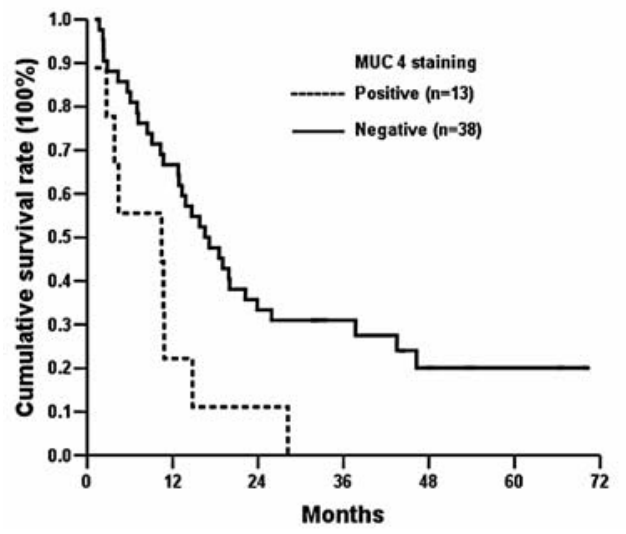

B.

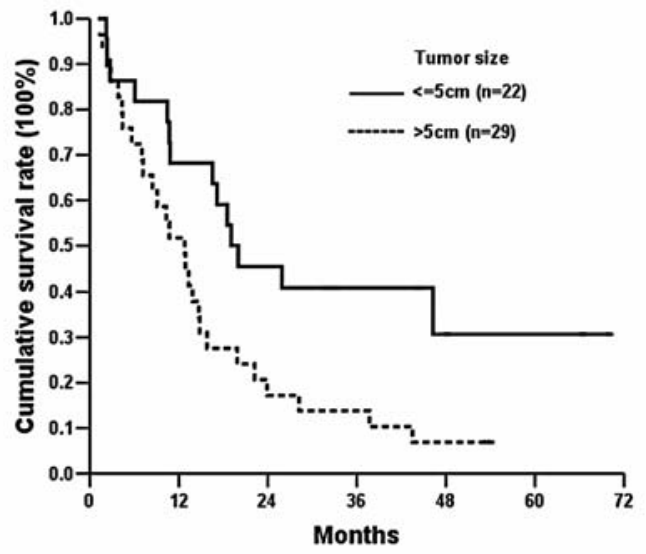

D.

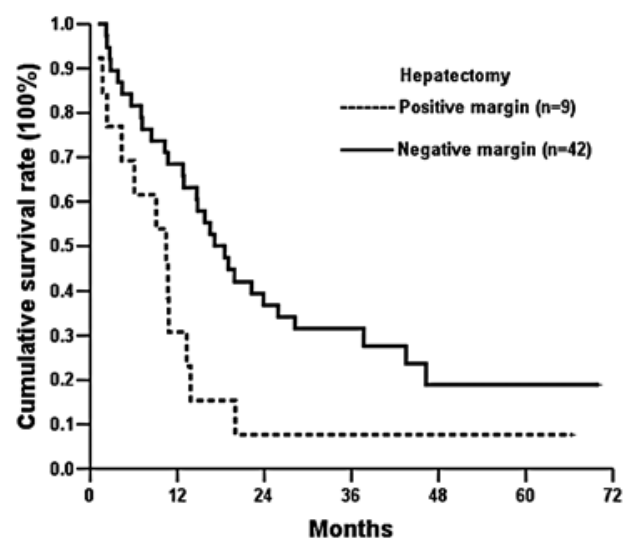

Figure 3. Overall survival rate of 51 MF-PCC patients undergoing hepatectomy in terms of tumor size, MUC-4 staining status, and resection margin (A-D, respectively).

forward 5'-ATACATCAACTACATCAGCC-3' and reverse 5'-CTCTGAGGAAGTGTTGTTAT-3' and housekeeping gene (ACTIN) forward 5'-GACAGGATGCAGAAGGA GAT-3' and reverse. 5'-CTGCTTGCTGATCCACATCT-3'. Q-RT-PCR cycle conditions were $3 \mathrm{~min}$ at $95^{\circ} \mathrm{C}, 15 \mathrm{sec}$ at $95^{\circ} \mathrm{C}$ and $45 \mathrm{sec}$ at $56^{\circ} \mathrm{C}$ for 45 cycles. Performing primer matrix reactions and generating standard curves for MUC4 and ACTIN determined optimal PCR conditions. PCR reactions were performed in triplicate and the relative expression level of MUC4 in normal and tumor tissue was calculated by normalizing to ACTIN expression level using the comparative CT method. CT represents the cycle numbers at which the amplification reaches a threshold level chosen to lie in the exponential phase of all PCR reactions. Data were analyzed using the iCycle iQ system software (BioRad, Hercules, CA).

Immunohistochemical staining of MUC4 in rat CCA. A $4 \mu \mathrm{m}$ section of thioacetamide induced rat CCA tissue was stained for MUC-4. The primary antibody MUC4 (mouse antiMUC4 monoclonal antibody, ZYMED 35-4900) was diluted to $1: 1500$ and was added to the slides to be incubated overnight at $4^{\circ} \mathrm{C}$. The slides were then washed 3 times for 5 min in TBST before visualization with the 'Dako LSAB2 System, Peroxidase' (Dako A/S, No. K0675). Control slides were incubated with a secondary antibody only. After washing 3 times for 5 min each in TBST, the slides were mounted and blindly analyzed under microscope by authors.
Clinicopathological features of human CCA. CCA was defined as carcinoma arising from second order or more distal branches of the intrahepatic ducts. CCAs have been classified into three types based on the macroscopic appearance of the tumors, including mass-forming (MF), periductal infiltrating, and intraductal papillary type CCA. Curative resection was defined as negative resection margin observed during histopathological examination. Two patients were excluded from survival analysis due to surgical mortality. Surgical mortality is defined as death occurring within one month after surgery. Laboratory tests were conducted on the day before surgery. Serum carbohydrate antigen 19-9 (CA 19-9) and carcinoembryonic antigen (CEA) were measured by radioimmunoassay. The tumors were preoperatively evaluated by abdominal ultrasonography, endoscopic retrograde cholangiopancreatography, percutaneous transhepatic cholangiography, computed tomography, magnetic resonance image with cholangiopancreatography, and hepatic arteriography, as appropriate. Tumor stage was defined according to the pathological tumor node metastasis (pTNM system) classification proposed by the AJCC 6th edition. Adjuvant chemotherapy was systemically performed with a 5-flurouracil-based regimen due to either a positive section margin or local recurrence.

Immunohistochemical staining of MUC4 in human CCA. From the archives of Chang Gung Memorial Hospital, 53 MF-CCA patients undergoing hepatectomy between 2000 
Table I. Univariate analysis of factors influencing the overall survival of the $51 \mathrm{MF}-\mathrm{CCA}$ patients.

\begin{tabular}{|c|c|c|c|c|c|}
\hline \multirow[t]{2}{*}{ Factors } & \multicolumn{4}{|c|}{ Survival time (months) } & \multirow[t]{2}{*}{$\mathrm{P}$} \\
\hline & Median & Mean & 3 -year $(\%)$ & 5-year (\%) & \\
\hline \multicolumn{6}{|l|}{ Gender } \\
\hline Male $(n=25)$ & 16.5 & 24.4 & 24.0 & 16.0 & \\
\hline Female $(n=26)$ & 12.8 & 22.8 & 26.9 & 16.8 & 0.7932 \\
\hline \multicolumn{6}{|l|}{ Symptoms } \\
\hline Positive $(n=40)$ & 10.7 & 17.4 & 17.5 & 13.1 & \\
\hline Negative $(\mathrm{n}=11)$ & 37.7 & 41.0 & 54.6 & 32.7 & 0.0107 \\
\hline \multicolumn{6}{|l|}{ AST (IU/l) } \\
\hline$\leq 34(n=24)$ & 13.8 & 30.2 & 37.5 & 30.0 & \\
\hline$>34(n=27)$ & 14.7 & 17.8 & 14.8 & 7.4 & 0.1452 \\
\hline \multicolumn{6}{|l|}{$\operatorname{ALT}(\mathrm{IU} / \mathrm{l})$} \\
\hline$\leq 36(n=28)$ & 15.8 & 29.0 & 34.6 & 27.7 & \\
\hline$>36(n=23)$ & 14.7 & 18.1 & 14.3 & 4.8 & 0.2070 \\
\hline \multicolumn{6}{|l|}{ ALP (IU/l) } \\
\hline$\leq 94(n=21)$ & 18.5 & 30.1 & 31.6 & 31.6 & \\
\hline$>94(\mathrm{n}=30)$ & 10.7 & 18.9 & 20.7 & 8.3 & 0.0952 \\
\hline \multicolumn{6}{|l|}{ Bil (total) (mg/dl) } \\
\hline$\leq 1.3(\mathrm{n}=45)$ & 14.8 & 24.3 & 26.7 & 16.0 & \\
\hline$>1.3(\mathrm{n}=6)$ & 10.7 & 17.6 & 16.7 & 16.7 & 0.7059 \\
\hline \multicolumn{6}{|l|}{ Albumin (g/dl) } \\
\hline$\leq 3.5(\mathrm{n}=12)$ & 4.4 & 10.4 & 10.0 & 10.0 & \\
\hline$>3.5(\mathrm{n}=39)$ & 17.2 & 26.5 & 29.0 & 17.4 & 0.0094 \\
\hline \multicolumn{6}{|l|}{ Serum CEA (ng/dl) } \\
\hline$<5(n=24)$ & 17.2 & 26.3 & 41.2 & 30.9 & \\
\hline$\geq 5(n=27)$ & 10.7 & 16.4 & 10.5 & 10.5 & 0.1017 \\
\hline
\end{tabular}

AST, aspartate aminotransferase; ALT, alanine amionotransferase; ALP, alkaline phosphatase; CEA, carcinoembryonic antigen; CA 19-9, carbohydrate antigen; IU, international unit.

and 2004 were selected based on the availability of sufficient quantities of tumor cells. H\&E-stained slides from each case were reviewed. A $4 \mu \mathrm{m}$ section of MF-CCA undergoing hepatectomy from formalin-fixed, paraffin-embedded tissue was stained for MUC-4. The primary antibody MUC4 (mouse anti-MUC4 monoclonal antibody, ZYMED 35-4900) was diluted to $1: 1500$ and was added to the slides to be incubated overnight at $4^{\circ} \mathrm{C}$. The slides were then washed 3 times for $5 \mathrm{~min}$ in TBST before visualization with the 'Dako LSAB2 System, Peroxidase' (Dako A/S, No. K0675). Control slides were incubated with a secondary antibody only. After washing 3 times for $5 \mathrm{~min}$ each in TBST, the slides were mounted and blindly analyzed under microscope by authors and labeling of cholangiolar epithelium was scored as negative ( $<1 \%$ staining); 1 positive (1-10\% staining), 2 positive (10$25 \%$ ), 3 positive $(25-50 \%)$, and 4 positive (>50\% staining).

Follow-up study. Follow-up evaluation included clinical physical examinations and blood chemistry tests at each visit. Additionally, serum CEA and CA 19-9 were measured, and the remnant liver was examined with ultrasonography (US) every three months. When US detected a new lesion or elevated CEA/CA 19-9 was noted, abdominal CT or MRCP was performed for confirmation. Moreover, when patients complained of bone pain, bone scans were performed to detect metastasis. If any of the above procedures indicated recurrence, the patient was readmitted for more comprehensive assessment, including angiographic evaluation or MRI. Methods for treating a recurrence include surgery, systemic chemotherapy, external beam radiotherapy, intraluminal radiotherapy, interventional radiological therapy, and conservative treatment.

Statistical analysis. The overall survival rates were calculated with the Kaplan-Meier method. Fifteen clinicopathological variables were selected for difference analysis by the log-rank test. The Cox proportional hazards model was employed for multivariate regression analysis. SPSS for Windows statistics software (SPSS version 10.0, Chicago, IL) was used for the 
Table II. Univariate analysis of factors influencing the overall survival of the $51 \mathrm{MF}-\mathrm{CCA}$ patients.

\begin{tabular}{|c|c|c|c|c|c|}
\hline \multirow[t]{2}{*}{ Factors } & \multicolumn{4}{|c|}{ Survival time (months) } & \multirow[t]{2}{*}{$\mathrm{P}$} \\
\hline & Median & Mean & 3 -year (\%) & 5 -year (\%) & \\
\hline \multicolumn{6}{|l|}{ Associated with IHD stones } \\
\hline With IHD stones $(n=13)$ & 10.3 & 15.8 & 15.4 & 15.4 & \\
\hline Without IHD stones $(n=38)$ & 14.8 & 26.0 & 29.0 & 17.4 & 0.1794 \\
\hline \multicolumn{6}{|l|}{ Hepatectomy } \\
\hline Curative $(n=42)$ & 16.5 & 27.0 & 30.1 & 20.1 & \\
\hline Non-curative $(n=9)$ & 10.5 & 9.7 & 0 & 0 & 0.0085 \\
\hline \multicolumn{6}{|l|}{ Tumor differentiation } \\
\hline Well $(n=6)$ & 4.4 & 21.6 & 33.3 & 16.7 & \\
\hline Moderate $(n=26)$ & 15.8 & 22.9 & 26.9 & NA & \\
\hline Poor $(n=19)$ & 13.3 & 23.3 & 21.1 & 21.1 & 0.794 \\
\hline \multicolumn{6}{|l|}{ Lymph node } \\
\hline Positive $(\mathrm{n}=18)$ & 12.8 & 14.9 & 11.1 & 11.1 & \\
\hline Negative $(n=33)$ & 19.0 & 28.0 & 33.3 & 20 & 0.0467 \\
\hline \multicolumn{6}{|l|}{ Tumor size } \\
\hline$\leq 5 \mathrm{~cm}(\mathrm{n}=22)$ & 19.0 & 33.6 & 40.9 & 30.7 & \\
\hline$>5 \mathrm{~cm}(\mathrm{n}=29)$ & 12.8 & 15.9 & 13.8 & 6.9 & 0.0132 \\
\hline \multicolumn{6}{|l|}{ Post-operative chemotherapy } \\
\hline Positive $(n=31)$ & 14.8 & 22.8 & 19.4 & 14.5 & \\
\hline Negative $(n=20)$ & 7.2 & 24.6 & 35.0 & 18.7 & 0.9789 \\
\hline \multicolumn{6}{|l|}{ Post-operative complication } \\
\hline Positive $(n=7)$ & 7.2 & 19.9 & 28.6 & 28.6 & \\
\hline Negative $(n=44)$ & 14.7 & 23.9 & 25.0 & 15.0 & 0.8242 \\
\hline \multicolumn{6}{|l|}{ MUC-4 staining } \\
\hline Positive (13) & 10.5 & 13.1 & 7.7 & 0 & \\
\hline Negative (38) & 17.2 & 27.4 & 31.6 & 19.0 & 0.018 \\
\hline
\end{tabular}

IHD, intrahepatic duct.

statistical analysis. $\mathrm{P} \leq 0.05$ was considered statistically significant.

\section{Results}

Quantitative real-time PCR. Fig. 1A showed a significantly higher expression of MUC4 in six rat CCAs compared with six liver tissues of non-tumor parts demonstrated by quantitative real-time PCR. The fold of expression of MUC4 regarding tumor to a normal liver ranges from 1.74 to 18.81 folds.

MUC4 staining status in rat and human CCA. MUC4 is diffusely expressed in cytoplasmic and membranous distribution in human and rat CCA but is absent in normal hepatocyte (Fig. 1B). Fig. 2 showed the picture of various positive staining of MUC4 in human CCA. Fifteen (28.3\%) out of $53 \mathrm{CCA}$ patients had various strengths of positive
MUC4, 1 positive (5), 2 positive (3), 3 positive (1), 4 positive (6), respectively.

Survival and prognostic analysis for human MF-CCA patients undergoing hepatectomy. Fifty-three MF-CCA patients, including 26 men and 27 women with a median age of 60 years (range: 29-89 years), undergoing hepatectomy received regular follow-up until death. Two patients who died within one month after surgery were excluded from the survival analysis (surgical mortality rate: $3.8 \%$ ). In total, 51 MF-CCA patients undergoing hepatectomy were enrolled in the survival analysis study. The follow-up duration ranged from 1.1 to 70.1 months (median, 14.7 months). Overall survival (OS) rates at 1, 3, and 5 years were $58.8 \%, 25.5 \%$, and $16.5 \%$, respectively (Fig. 3A).

Univariate log-rank analysis identified adverse influences on OS rate of 51-MF CCA patients undergoing hepatectomy as follows: presence of symptoms, preoperative lower 
Table III. Cox's proportional hazards analysis.

\begin{tabular}{|c|c|c|}
\hline Factors & $\begin{array}{c}\text { Relative risk } \\
\text { (95\% confidence } \\
\text { interval) }\end{array}$ & $\mathrm{P}$ \\
\hline Symptoms (positive/negative) & & NS \\
\hline $\operatorname{Albumin}(\leq 3.5 \mathrm{~g} / \mathrm{dl} />3.5 \mathrm{~g} / \mathrm{dl})$ & & NS \\
\hline Tumor size $(>5 \mathrm{~cm} / \leq 5 \mathrm{~cm}$ & $2.20(1.09-4.42)$ & 0.028 \\
\hline $\begin{array}{l}\text { Hepatectomy (positive margin/ } \\
\text { negative margin) }\end{array}$ & $2.85(1.19-6.85)$ & 0.019 \\
\hline $\begin{array}{l}\text { Lymph node status } \\
\text { (positive/negative) }\end{array}$ & & NS \\
\hline $\begin{array}{l}\text { MUC-4 staining } \\
\text { (positive/negative) }\end{array}$ & $3.40(1.56-7.41)$ & 0.002 \\
\hline
\end{tabular}

albumin level, tumor size $>5 \mathrm{~cm}$, positive lymph node metastasis, MUC4 staining, and positive surgical margin status (Tables I and II). Meanwhile, multivariate Cox's proportional hazard analysis demonstrated that tumor size $>5$ $\mathrm{cm}$, presence of MUC4 staining, and non-curative hepatectomy were the three independent prognostic factors that adversely affected OS rates (Table III, Fig. 3B-D).

\section{Discussion}

Although the molecular alterations involved in human CCA tumorigenesis have not been investigated thoroughly, our TAA induced rat CCA model may serve as a powerful preclinical platform. TTA and furan models of rat cholangiocarcinogenesis described that the receptors of tyrosine kinase c-Met and c-erb-B2 were overexpressed in the neoplastic glands of invasive CCAs, while absent or minimal in normal cholangiolar epithelium $(13,35)$. Notably, striking up-regulation of the two oncogenes was noted in the epithelial cells of dysplastic glands as early as in the 9th week of TAA administration, and persisted into the invasive phase CCA $(13,35)$. Recently, we demonstrated that MUC4 was overexpressed in TTA induced rat CCA by DNA microarray genomic study (data not shown). This study also showed an over-expression of MUC4 in rat CCA by quantitative RT-PCR and validated its prognostic value in human MF-CCA after hepatectomy.

This study used univariate and multivariate analysis to calculate overall survival (OS) rates of $53 \mathrm{MF}-\mathrm{CCA}$ patients after hepatic resection in terms of 15 clinicopathologic factors, including MUC-4 staining status. In univariate analysis, absence of physical findings, better nutritional status, small tumor size, negative lymph node metastasis, absence of MUC4 staining, and curative hepatic resection were associated with favorable OS rate for MF-CCA patients after hepatectomy. Applying the multivariate Cox's proportional hazard model to data from this investigation revealed that favorable overall survival depends on an absence of MUC4 staining, small tumor size, and curative hepatectomy.

MUC4 is normally expressed in normal tissues of the respiratory tract, stomach, small intestine, colon, and endocervix (23-26). Previously, MUC4 has been demonstrated as a novel intramembrane ligand for receptor tyrosine kinase Erb2 $(28,29)$. Ascites sialoglycoprotein-2, the transmembrane subunit of MUC4, showed specific binding to Erb2, and MUC4 binding to Erb2 induced tyrosine phosphorylation of the receptor. MUC4 is the only ligand that has been characterized for ErbB2 $(27,29)$. Clinically, MUC4 has been regarded as a candidate for a tumor marker of pancreatic adenocarcinoma and extrahepatic CCA. However, the relationship between MUC4 expression and the patient's prognosis in MF-CCA is limited (34). Similar to Shibahara's report (34), we found that MUC4 expression was significantly related to poor survival of the patients with MF-CCA in univariate survival analysis, and that the MUC4 expression is an independent poor prognostic factor in patients with MFCCA after hepatectomy.

Patients who had MF-CCA diagnosed asymptomatically and incidentally had a favorable survival, demonstrated by univariate survival analysis. However, this study revealed the fact that CCA remains clinically challenging because it is difficult to diagnose in its early stages, and patients typically do not present because of vague symptoms until the disease is quite advanced. This fact is demonstrated in more than half of the MF-CCA patients presented with tumor size $>5 \mathrm{~cm}$, so we should seek a certain novel tumor marker for the early detection of CCA in high-risk patient groups.

Diagnostic adjuncts for CCA, such as a serum marker, are useful for the clinical management of this disease. Several investigators have reported that CA 19-9 and CEA determinations are useful for diagnosing CCA in primary sclerosing cholangitis (36). These investigators also demonstrated that serum CA 19-9 values are related to tumor burden and suggested that values were elevated in patients with CCA related to unresectable disease (36). A previously conducted Japanese study also demonstrated that an elevated serum tumor marker, which includes CEA and CA19-9, was a predictor of a dismal prognosis (37). Although the reason is unclear, this study did not demonstrate its role as predictors of prognosis for MF-CCA patients after hepatectomy.

A previously published Japanese report proposed a new staging system based mainly on the MF-type CCA to challenge the TNM staging system (38); however, this study reveals that a TNM staging system remains the most reliable prognostic factor for predicting the outcome of MF-CCA patients undergoing hepatectomy. Similar to the Japanese reports, lymph node metastasis is a reliable prognostic factor to in predicting a considerably worse prognosis, demonstrated by univariate survival analysis $(39,40)$. MF-CCA patients with tumors $>5 \mathrm{~cm}$ undergoing hepatectomy displayed a considerably worse prognosis as determined by Cox's multivariate proportional hazard analysis.

Hepatic resection is the preferred treatment for CCA (1). This study demonstrated that MF-CCA patients undergoing 
curative hepatic resection exhibited significantly better OS rates than those who did not. Similar to IP-CCA patients, an absence of curative hepatic resection in MF-CCA patients increased the chances of reducing long-term OS rate by 2.85 times according to Cox's multivariate proportional hazard analysis (41-44). This fact emphasizes that curative hepatic resection warrants a long-term OS rate.

In conclusion, a favorable long-term OS rate of MF-CCA patients undergoing hepatectomy depends on negative MUC4 staining, smaller tumor size, and curative hepatectomy.

\section{Acknowledgements}

This work was supported by the Chang Gung Medical Research Program (CMRP) grants: 350361, 350362 and the National Medical Research Program (NMRP) grant: 340551 to Dr Chun-Nan Yeh.

\section{References}

1. Chen MF: Peripheral cholangiocarcinoma (cholangiocellular carcinoma): Clinical features, diagnosis and treatment. J Gastroenterol Hepatol 14: 1144-1149, 1999.

2. Liver Cancer Study Group of Japan. Classification of primary liver cancer. 1st English edition, Kanehara, Tokyo, 1997.

3. Weber SM, Jarnagin WR, Klimstra D, DeMatteo RP, Fong Y and Blumgart LH: Intrahepatic cholangioc-arcinoma: Resectability, recurrence pattern, and outcomes. J Am Coll Surg 193: 384-391, 2001.

4. Uenishi T, Hirohashi K, Kubo S, Yamamoto T, Hamba H, Tanaka $\mathrm{H}$ and Kinoshita $\mathrm{H}$ : Histologic factors affecting prognosis following hepatectomy for intrahepatic cholangiocarcinoma. World J Surg 25: 865-869, 2001

5. Jarnagin WR, Fong Y and DeMatteo RP: Staging, resectability, and outcome in 225 patients with hilar cholangiocarcinoma. Ann Surg 234: 507-519, 2001.

6. de Groen PC, Gores GJ, LaRusso NF, Gunderson LL and Nagorney DM: Biliary tract cancers. N Engl J Med 341: 1368-1378, 1999.

7. Patel T: Increasing incidence and mortality of primary intrahepatic cholangiocarcinoma in the United States. Hepatology 33: 1353-1357, 2001

8. Shirabe K, Shimada M and Harimoto N: Intrahepatic cholangiocarcinoma: Its mode of spreading and therapeutic modalities. Surgery 131: S159-S164, 2002.

9. Bathe OF, Pacheco JT and Ossi PB: Management of hilar bile duct carcinoma. Hepatogastroenterology 48: 1289-1294, 2001.

10. Terada T, Nakanuma Y and Sirica AE: Immunohistochemical demostration of MET overexpression in human intrahepatic cholangiocarcinoma and in hepatolithiasis. Hum Pathol 29, $175-180,1998$

11. Endo K, Yoon BI, Pairojkul C, Demetris AJ and Sirica AE: ERBB-2 overexpression and cyclooxygenase-2 up-regulation in human cholangiocarcinoma and risk conditions. Hepatology 36: 439-450, 2002.

12. Hansel DE, Rahman A, Hidalgo M, et al: Identification of novel cellular targets in biliary tract cancers using global gene expression technology. Am J Pathol 163: 217-229, 2003.

13. Yeh CN, Maitra A, Lee KF, Jan YY and Chen MF: Thioacetamide-induced intestinal type cholangiocarcinona in rat: an animal model recapitulating the multi-stage progression of human cholangiocarcinoma. Carcinogenesis 25: 631-636, 2004.

14. Yonezawa $\mathrm{S}$ and Sato E: Expression of mucin antigens in human cancers and its relationship with malignancy potential. Pathol Int 47: 813-830, 1997.

15. D'Cruz OJ, Haas G, Dunn TS, Sachdev GP and Pichan P: Antigenic crossreactivity of human tracheal mucin with 8 gene messenger ribonucleic acid in reproductive tract tissues. Fertil Steril 66: 316-326, 1996.

16. Lapensee L, Paquette Y and Bleau G: Allelic polymorphism and chromosomal localization of the human oviductin gene (MUC9). Fertil Steril 68: 702-708, 1997.
17. Williams SJ, McGuckin MA, Gotley DC, Eyre HJ, Sutherland GR and Antalis TM: Two novel mucin genes downregulated in colorectal cancer identified by differential display. Cancer display. Cancer Res 59: 4083-4089, 1999.

18. Williams SJ, Wreshner DH, Tran M, Eyre HJ, Sutherland GR and McGuckin MA: Muc13, a novel human cell surface mucin expressed by epithelial and hemopoietic cells. J Biol Chem 276: 18327-18336, 2001.

19. Pallesen LT, Berglund L, Rasmussen LK, Petersen TE and Rasmussen JT: Isolation and characterization of MUC15, a novel cell membrane-associated mucin. Eur J Biochem 269: 2755-2763, 2002

20. Yin BW, Dnistrian A and Lloyd KO: Ovarian cancer antigen CA 125 is encoded by the MUC 16 mucin gene. Int J Cancer 98: 737-740, 2002.

21. Gum JR Jr, Crawley SC, Hicks JW, Szymkowski DE and Kim YS: MUC17, a novel membrane-tethered mucin. Biochem Biophys Res Commun 291: 466-475, 2002.

22. Porchet N, Cong NV, Dufosse J, Audie JP, Guyonnet-Duperat V, Gross MS, Denis C, et al: Molecular cloning and chromosomal localization of a novel human tracheo-bronchial mucin cDNA containing tandemly repeated sequences of 48 base pairs. Biochem Biophys Res Commun 175: 414-422, 1991.

23. Audie JP, Janin A, Prochet N, Copin MC, Gosselin B and Aubert JP: Expression of human mucin gene in respiratory, digestive, and reproductive tracts ascertained by in situ hybridization. J Histochem Cytochem 41: 1479-1485, 1993.

24. Audie JP, Tetaret D, Pignu P, Buisine MP, Janin A, Aubert JP, Prochet $\mathrm{N}$, et al: Mucin gene expression in the human endocervix. Hum Reprod 10: 98-102, 1995.

25. Gipson IK, Spurr-Michaud S, Moccia R, Zhan Q, Toribara N, Ho SB, Gargiulo AP, et al: MUC4 and MUC5B transcripts are the prevalent mucin messenger ribonucleic acids of the human endocervix. Biol Reprod 60: 58-64, 1999.

26. Buisine MP, Devisme L, Copin MC, Durand-Reville M, Gosselin B, Aubert JP and Porchet N: Developmental mucin gene expression in the human respiratory tract. Am J Respir Cell Mol Biol 20: 209-218, 1999.

27. Moniaux N, Nollet S, Porchet N, Degand P, Laine A and Aubert JP: Complete sequence of the human mucin MUC4: a putative cell membrane-associated mucin. Biochem J 338: 325-333, 1999.

28. Carraway III KL, Rossi EA, Komatsu M, Price-Schiavi SA, Huang D, Guy PM, Carvajal ME, et al: An intramembrane modulator of the ErbB2 receptor tyrosine kinase that potentiates neuregulin signaling. J Biol Chem 274: 5263-5266, 1999.

29. Carraway KL, Ramsauer VP, Haq B and Carothers Carraway CA: Cell signaling through membrane mucins. Bioessays 25: 66-71, 2003.

30. Takao S, Uchikura K, Yonezawa S, Shinchi H and Aikou T: Mucin core protein expression in extrahepatic bile duct carcinoma is associated with metastasis to the liver and poor prognosis. Cancer 86: 1966-1975, 1999.

31. Matsumura N, Yamamoto M, Aruga A, Takasaki K and Nakano M: Correlation between expression of MUC1 core protein and outcome after surgery in mass-forming intrahepatic cholangiocarcinoma. Cancer 94: 1770-1776, 2002.

32. Tamada S, Goto M, Nomoto M, Nagata K, Shimizu T, Tanaka S, Sakoda K, et al: Expression of MUC1 and MUC2 mucins in extrahepatic bile duct carcinoma: its relationship with tumor progression and prognosis. Pathol Int 52: 713-723, 2002.

33. Lee KT and Liu TS: Altered mucin gene expression in stonecontaining intrahepatic bile ducts and cholangiocarcinomas. Dig Dis Sci 46: 2166-2172, 2001.

34. Shibahara H, Tamada S, Higashi M, et al: MUC4 is a novel prognostic factor of intrahepatic cholangiocarcinoma - Mass forming type. Hepatology 39: 220-229, 2004.

35. Elmore LW and Sirica AE: 'Intestinal-type' of adenocarcinoma preferentially induced in right/caudate liver lobes of rats treated with furan. Cancer Res 53: 254-259, 1993.

36. Andrianifahanana M, Moniaux N, Schmied BM, Ringel J, Friess H, Hollingsworth MA, Buchler MW, et al: Mucin (MUC) gene expression in human pancreatic adenocarcinoma and chronic pancreatitis: a potential role of MUC4 as a tumor marker of diagnostic significance. Clin Cancer Res 7: 4033-4040, 2001.

37. Swartz MJ, Batta SK, Varshney GC, Hollingsworth MA, Yeo CJ, Cameron JL, Wilentz RE, et al: MUC 4 expression increases progressively in pancreatic intraepithelial neoplasia. Am J Clin Pathol 117: 791-796, 2002. 
38. Tamada S, Shibahara H, Higashi M, Goto M, Batra S, Imai K and Tonezawa S: MUC4 is a novel prognostic factor of extrahepatic bile duct carcinoma. Clin Cancer Res !2: 4257-4264, 2006.

39. Okabayashi T, Yamamoto J, Kosuge T, Shimada K, Yamasaki S, Takayama T and Makuuchi M: The utility of CA 19-9 in the diagnoses of cholangiocarcinoma in patients without primary sclerosing cholangitis. Am J Gastroenterol 95: 204-207,2000.

40. Ohtsuka M, Ito H, Kimura F, Shimizu H, Togawa A, Yoshidome $\mathrm{H}$ and Miyazaki M: Results of surgical treatment for intrahepatic cholangiocarcinoma and clinicopathological factors influencing survival. Br J Surg 89: 1525-1531, 2002.

41. Okabayashi T, Yamamoto J, Kosuge T, Shimada K, Yamasaki S, Takayama T and Makuuchi M: A new staging system for massforming intrahepatic cholangiocarcinoma: Analysis of preoperative and postoperative variables. Cancer 92: 2374-2383, 2001 .
42. Uenishi T, Hirohashi K, Kubo S, Yamamoto T, Yamazaki O and Kinoshita H: Clinicopathological factors predicting outcome after resection of mass-forming intrahepatic cholangiocarcinoma. Br J Surg 88: 969-974, 2001.

43. Inoue K, Makuuchi M, Takayama T, et al: Long-term survival and prognostic factors in the surgical treatment of mass-forming type cholangiocarcinoma. Surgery 127: 498-505, 2000.

44. Yeh CN, Jan YY, Yeh TS, Hwang TL and Chen MF: Hepatic resection of intraductal papillary type of cholangiocarcinoma. Ann Surg Oncol 11: 606-611, 2004 